\title{
STUDY OF METHYLENE BLUE ADSORPTION BY MODIFIED KAOLINITE BY DIMETHYL SULFOXIDE
}

\begin{abstract}
Tamazert kaolin was modified with dimethyl sulfoxide (DMSO). The starting material and resulting from the intercalation were characterized by X-ray diffraction, Fourier transform infrared spectroscopy and scanning electron microscopy (SEM). Intercalation caused considerable changes in our clay by increasing the basal spacing to $11.22 \AA$, an intercalation rate of $98 \%$. The adsorption of methylene blue was studied as a function of $\mathrm{pH}$, contact time, temperature, dye concentrations and adsorbents. Kinetic data have been adequately described by the pseudo-second order and intraparticle scattering model. The adsorption isotherm is in good agreement with the Redlich-Peterson model. A change in thermodynamic values $\left(\Delta H^{\circ}, \Delta S^{\circ}\right.$ and $\left.\Delta G^{\circ}\right)$ was observed after intercalation. Adsorption became non-spontaneous exothermic and ordered.
\end{abstract}

Keywords: kaolin, DMSO, intercalation, adsorption, methylene blue

\section{Introduction}

Dyes are widely used in industries such as textiles, paper, leather, rubber, plastics, dyes synthesis, printing, food, pharmaceutical and cosmetic industries. The dyes generally have a synthetic origin and complex aromatic molecular structures that make them more stable and more difficult to biodegrade. Many organic dyes are harmful to humans and toxic to microorganisms, the elimination of dyes from sewage has received considerable attention in recent decades [1-3].

Currently, several techniques are used for the removal of pollutants. Among these, we can mention chemical precipitation, ion exchange, electrochemical treatment, reverse osmosis and adsorption. Chemical precipitation is inappropriate to remove low concentrations and produces a large amount of sludge. Despite its effectiveness, reverse osmosis is an expensive technique because it requires frequent replacement of membranes.

\footnotetext{
${ }^{1}$ Laboratory of Plant Physiology Applied to Above-Soil Culture, Department of Nature and Life Sciences, University of Tiaret BP 78 Zaaroura, Tiaret 14000, Algeria, phone +213774667389, fax +21323522042, email: lellousalima@yahoo.fr

${ }^{2}$ Improvement and Enhancement of Local Animal Production Laboratory, Department of Nature and Life Sciences, University Centre Ahmed Ben Yahia Al-wancharissi, Tissemsilt 38000, Algeria, phone +213794429055 , fax +21323522042, email: aidgue@gmail.com

${ }^{3}$ Geosciences Environment Laboratory Toulouse (GET), CNRS-IRD-OMP - Toulouse University, 14, Avenue Edouard Belin, 31400 Toulouse, France, phone +330561332647, fax +330561332560, email: jacques.schott@get.omp.eu

${ }^{4}$ Department of Material Sciences, University of Tiaret BP 78 Zaaroura, Tiaret 14000, Algeria, phone +213778216383 , fax +21323522042 , email: benhebalh@yahoo.fr

*Corresponding author: ksam792002@yahoo.fr
} 
Ion exchange is also a costly operation, while electrolytic processes are considered cost effective only for concentrated solutions [4-7]. Adsorption has proved to be an effective, economical and easy to implement technique. In addition, there is no formation of sludge. Its other advantages are applicability at very low concentrations and the possibility of regeneration, for continuous or discontinuous use.

A large number of studies have been reported on use of different materials for dye removal from aqueous solution: crystal violet with palm petiole-derived biochar [8], congo red with cetyltrimethylammonium bromide-graphene oxide composite [9], methylene blue with reduced-graphene oxide supported nanoadsorbents [10], basic blue 41 with organic-inorganic hybrid adsorbent material [11] etc.

The modification of clays by organic or inorganic agents has attracted the interest of several researchers for their applications in various scientific and industrial fields [12]. Intercalation is one of the most sought after changes. The intercalation is one of the most sought after modifications at the moment. Intercalation is one of the most popular modifications currently in progress. The intercalation of kaolinite was born in 1960 and since that time until now, the industrial uses of intercalated kaolinite continues to grow. This growth is directly linked to its reactivity and these surface properties, which are remarkably improved after modification [13]. Kaolinite has been intercalated by several polar compounds such as: N-methyl formamide [14], urea [15], potassium acetate [16-18], hydrazine hydrate [19] and dimethyl sulfoxyde [20, 21]. These compounds are known to have the ability to break the interfoliar bond between the siloxane and hydroxy aluminium surfaces and to access the interfoliar space and thus forming a complex by hydrogen bonds at both surfaces [22].

This work investigated the feasibility of Algerian kaolin intercalated by DMSO, used as a low-cost adsorbent for the removal of methylene blue from an aqueous solution. The materials were characterised by X-ray diffraction (XRD), FTIR analysis and scanning electron microscope (SEM). To achieve the aim, the effects of adsorbent dosage, $\mathrm{pH}$, contact time, methylene blue (BM) concentration, and solution temperature were studied. Kinetic data, equilibrium isotherms, and thermodynamic parameters were also determined and discussed.

\section{Materials and methods}

\section{Materials}

Kaolin of Tamazert from Djebel Debbagh, Guelma (eastern region of Algeria) is commercialized without additives by SOAKLA society. Before the experiments, kaolin was ground, ultrasonically dispersed in deionised water, centrifuged and dried at $373 \mathrm{~K}, 10 \mathrm{~g}$ of kaolin were dispersed in $100 \mathrm{~cm}^{3}$ of DMSO, and the whole is subjected to moderate stirring for $96 \mathrm{~h}$ at room temperature. The excess solution was removed, and the kaolin, separated by centrifugation, was oven dried at $333 \mathrm{~K}$ [23]. The starting materials and the resulting products were respectively abbreviated to $\mathrm{K}$ and $\mathrm{KD}$ and characterized.

Methylene blue (BM), a cationic dye, was used as an adsorbate. The characteristics of the dye are listed in Table 1. 
Properties and characteristics of MB

\begin{tabular}{|c|c|}
\hline Generic name & Methylene blue \\
\hline Chemical name (IUPAC) & $\begin{array}{c}\text { 3,7-bis(Dimethylamino)-phenazathionium } \\
\text { chloride tetramethylthionine chloride }\end{array}$ \\
\hline Chemical formula & $\mathrm{C}_{16} \mathrm{H}_{18} \mathrm{ClN}_{3} \mathrm{~S} \cdot 3 \mathrm{H}_{2} \mathrm{O}$ \\
\hline Molecular weight $[\mathrm{g} / \mathrm{mol}]$ & 373.90 \\
\hline $\begin{array}{c}\text { Molecular volume } \\
{\left[\mathrm{cm}^{3} / \mathrm{mol}\right]}\end{array}$ & 241.9 \\
\hline Molecular diameter [nm] & 0.80 \\
\hline$\lambda$ specific [nm] & \\
\hline Chemical structure &
\end{tabular}

\section{Characterisation}

The X-ray powder diffraction patterns were obtained using a RIGAKU diffractometer (Netherlands) with CuKa radiation operating at $40 \mathrm{kV}$ and $25 \mathrm{~mA}$. The XRD data were collected over a $2 \mathrm{~h}$ range of 5-30 ${ }^{\circ}$ with a step width of $0.01^{\circ}$. The IR spectra were acquired through a Fourier transform spectrometer. The device used is SHIMADZU (FTIR-8400S). The structure band region (400-4000 $\mathrm{cm}^{-1}$ ) was investigated using $\mathrm{KBr}$ wafers containing $0.5 \%$ of sample. The morphological analysis is performed by a JSM-7200F scanning electron microscope with a field effect gun (Schottky).

\section{Adsorption procedure}

The adsorption experiments of methylene blue were performed via the batch method at 298 K. $0.02 \mathrm{~g}$ of the clay were mixed with $20 \mathrm{dm}^{3}$ of methylene blue in a concentration range of $10-400 \mathrm{mg} / \mathrm{dm}^{3}$. The effects of dye and adsorbent concentrations, $\mathrm{pH}$, contact time, and temperature were studied. The experimental conditions are outlined in Table 2. $\mathrm{pH}$ of the dispersions was adjusted by adding negligible volumes of $0.1 \mathrm{M} \mathrm{HCl}$ or $0.1 \mathrm{M} \mathrm{NaOH}$. After each experiment, the solution was separated by filtration. The filtrate was analysed by visible spectrophotometry at $\lambda=660 \mathrm{~nm}$ using a Shimadzu 1240 UV-VIS spectrophotometer.

Experimental conditions during the adsorption of methylene blue

\begin{tabular}{|c|c|}
\hline Adsorbent concentration & $\begin{array}{c}\text { Clay: } 1,2,3,4,5,6,7,8,9 \text { and } 10 \mathrm{~g} / \mathrm{dm}^{3} \\
\text { Temperature } 298 \mathrm{~K} \text {, contact time } 2 \mathrm{~h}\end{array}$ \\
\hline $\mathrm{pH}$ & $\begin{array}{c}\mathrm{pH}(\mathrm{BM}): 2,3,4,5,6,7,8,9 \text { and } 10 \\
\text { Clay } 1 \mathrm{~g} / \mathrm{dm}^{3} \text {, temperature } 298 \mathrm{~K} \text {, contact time } 2 \mathrm{~h}\end{array}$ \\
\hline Kinetics & $\begin{array}{c}\text { Contact time: } 1,3,5,10,20,30,60,90 \text { and } 120 \mathrm{~min} \\
\text { Clay } 1 \mathrm{~g} / \mathrm{dm}^{3} \text {, temperature } 298 \mathrm{~K}, \mathrm{pH}=5\end{array}$ \\
\hline Isotherms & $\begin{array}{l}\text { BM concentration: } 10,20,40,60,100,150,200,300 \text { and } 400 \mathrm{mg} / \mathrm{dm}^{3} \text {. } \\
\text { Clay } 1 \mathrm{~g} / \mathrm{dm}^{3} \text {, temperature } 298 \mathrm{~K} \text {, contact time } 1 \mathrm{~h}, \mathrm{pH}=5\end{array}$ \\
\hline Temperature & $\begin{array}{l}\text { Temperature: } 298,313 \text {, and } 328 \mathrm{~K} \text {. Clay } 1 \mathrm{~g} / \mathrm{dm}^{3}, \mathrm{BM}: 10,20,40,60,100 \text {, } \\
150,200,300 \text { and } 400 \mathrm{mg} / \mathrm{dm}^{3} \text {, contact time } 1 \mathrm{~h}, \mathrm{pH}=5\end{array}$ \\
\hline
\end{tabular}


The amounts of adsorbed BM [mg/g] were determined using the following equation:

$$
Q e=\frac{(C i-C e)}{m} V
$$

where $C i$ and $C e$ are the initial and the equilibrium dye concentrations $\left[\mathrm{mg} / \mathrm{dm}^{3}\right], V$ is the volume of dye solution used $\left[\mathrm{dm}^{3}\right]$, and $\mathrm{m}$ is the mass of material used $[\mathrm{g}]$.

\section{Theoretical considerations}

Adsorption kinetics

In order to investigate the controlling mechanism of adsorption processes, various kinetic equations are applied to model the kinetics of methylene blue adsorption onto the unmodified and modified kaolinites.

The first model that we used in our kinetic study is the pseudo-first order model which is given by the following relation [24]:

$$
\log (Q e-Q t)=\log Q e-\left(K_{1} \cdot t / 2.303\right)
$$

where $Q t$ is the amount adsorbed at time $t[\mathrm{mg} / \mathrm{g}], Q e$ the adsorption capacity at equilibrium $[\mathrm{mg} / \mathrm{g}], K_{1}$ the pseudo-first order rate constant [ $\left.\mathrm{min}^{-1}\right]$, and $t$ is the contact time [min].

The adsorption kinetics may also be described by a pseudo-second order reaction. The linearized-integral form of the model is [25]:

$$
t / Q t=\left(1 / K_{2} \cdot Q e^{2}\right)+t / Q e
$$

where $K_{2}$ is the pseudo-second order rate constant of adsorption $\left[\mathrm{g} \cdot(\mathrm{mg} \cdot \mathrm{min})^{-1}\right]$. The initial adsorption rate $h$, as $t \rightarrow 0$, can be defined as:

$$
h=K_{2} \cdot Q e^{2}
$$

The plot of $t / Q t$ versus $t$ should give a linear relationship, from which $K_{2}$ and $h$ can be determined from the slope and intercept of the plot.

During adsorption under batch mode, there is a possibility of transport of adsorbate species into the pores of adsorbent, which is often the rate-controlling step. The intraparticle diffusion rate equation can be written as follows [26]:

$$
Q t=K_{i d} \cdot t^{1 / 2}+C
$$

where $K_{i d}$ is the intraparticle diffusion rate constant $\left[\mathrm{mg} \cdot \mathrm{g}^{-1} \cdot \mathrm{min}^{-1 / 2}\right]$ and $C$ is a constant. The values $K_{i d}$ and $C$ are calculated from the slope and the intercept, respectively, of the plot of $Q t$ versus $t^{1 / 2}$.

\section{Adsorption isotherms modelling}

The equilibrium models of Langmuir, Freundlich, and Redlich-Peterson (RP) were used to fit the experimental data. The Langmuir equation can be written in the following form [27]:

$$
\frac{C e}{Q e}=\frac{1}{Q m K_{L}}+\frac{C e}{Q m}
$$

where $Q e$ is the equilibrium amount removed from solution $[\mathrm{mg} / \mathrm{g}], C e$ is the equilibrium concentration $\left[\mathrm{mg} / \mathrm{dm}^{3}\right], K_{L}$ is a constant related to the affinity of binding sites $\left[\mathrm{dm}^{3} / \mathrm{mg}\right]$, 
and $Q m$ is the maximum amount per unit weight of adsorbent for complete monolayer coverage $[\mathrm{mg} / \mathrm{g}]$.

The Freundlich model has been widely adopted and may be written in the form [28]:

$$
\log Q e=\log K_{F}+\frac{1}{n} \log C e
$$

where $K_{F}$ is a constant taken as an indicator of adsorption capacity $\left[\mathrm{dm}^{3} / \mathrm{g}\right.$ ] and $1 / n$ is a constant indicative of the adsorption intensity. The Redlich-Peterson model including three adjustable parameters was also used and is given by [29]:

$$
Q e=\frac{K_{R P} C e M}{1+\left(K_{R P} C e\right)^{\beta}}
$$

where $K_{R P}$ is the equilibrium constant $\left[\mathrm{dm}^{3} / \mathrm{mg}\right], \beta$ is the heterogeneity factor that depends on surface properties of the adsorbent, and $M$ is the maximum amount adsorbed $[\mathrm{mg} / \mathrm{g}]$.

\section{Thermodynamic study}

The thermodynamic parameters for the adsorption process, $\Delta G^{\circ}, \Delta H^{\circ}$ and $\Delta S^{\circ}$, were evaluated using the equation:

$$
\ln K_{d}=\left(\frac{-\Delta H^{\circ}}{\mathrm{R} \cdot T}\right)+\left(\frac{\Delta S^{\circ}}{\mathrm{R}}\right)
$$

where $\Delta H^{\circ}$ and $\Delta S^{\circ}$ are the change in enthalpy $[\mathrm{J} / \mathrm{mol}]$ and entropy $[\mathrm{J} /(\mathrm{mol} \cdot \mathrm{K})]$, respectively. $T$ the absolute temperature $[\mathrm{K}], \mathrm{R}$ gas constant $\left[\mathrm{J} \cdot(\mathrm{mol} \cdot \mathrm{K})^{-1}\right]$, and $K_{d}$ is the distribution coefficient $\left[\mathrm{dm}^{3} / \mathrm{g}\right]$. This coefficient is given by:

$$
K_{d}=Q e / C e
$$

The enthalpy and entropy changes are determined graphically by plotting $\ln K_{d}$ versus $1 / T$, which gives a straight line. According to thermodynamics, the Gibbs free energy change, $\Delta G^{\circ}$, is related to $\Delta H^{\circ}$ and $\Delta S^{\circ}$ at constant temperature by the following equation:

$$
\Delta G^{\circ}=\Delta H^{\circ}-T \cdot \Delta H^{\circ}
$$

\section{Results and discussion}

\section{XRD analysis}

The diffractograms of the different samples are shown in Figure 1. The DRX spectrum of the starting material, $\mathrm{K}$, shows intense basal reflections characteristic of kaolinite: a first at $7.15 \AA\left(2 \theta=12.41^{\circ}\right)$ corresponding to the $\left(\begin{array}{lll}0 & 0 & 1\end{array}\right)$ plane, a second at $04.47 \AA$ $\left(2 \theta=19.97^{\circ}\right)$, another at $03.59 \AA\left(2 \theta=25.01^{\circ}\right)$ and one last at $03.59 \AA\left(2 \theta=25.01^{\circ}\right)$. This shows that Tamazert kaolin is essentially kaolinite. Quartz (q) at low intensity was detected.

Chemical treatment with DMSO has caused a considerable change in our clay. Effectively, the X-ray diffraction shows an increase in the basal spacing of the reflection of the 001 lattice plane, from 7.16 to $11.22 \AA$. This increase in the basal distance is due to the intercalation of DMSO in the interfoliar space of our clay. To calculate the intercalation rate (IR), we used the relation of Wiewiora and Brindley [30] which is given by the following equation: 


$$
I R=\frac{I_{i 001}}{\left(I_{i 001}+I_{r 001}\right)}
$$

$I_{i 001}$ refers to the first reflection of the intercalated phase and $I_{r 001}$ is the residuary $\left(\begin{array}{lll}0 & 0 & 1\end{array}\right)$ reflection in the intercalate.

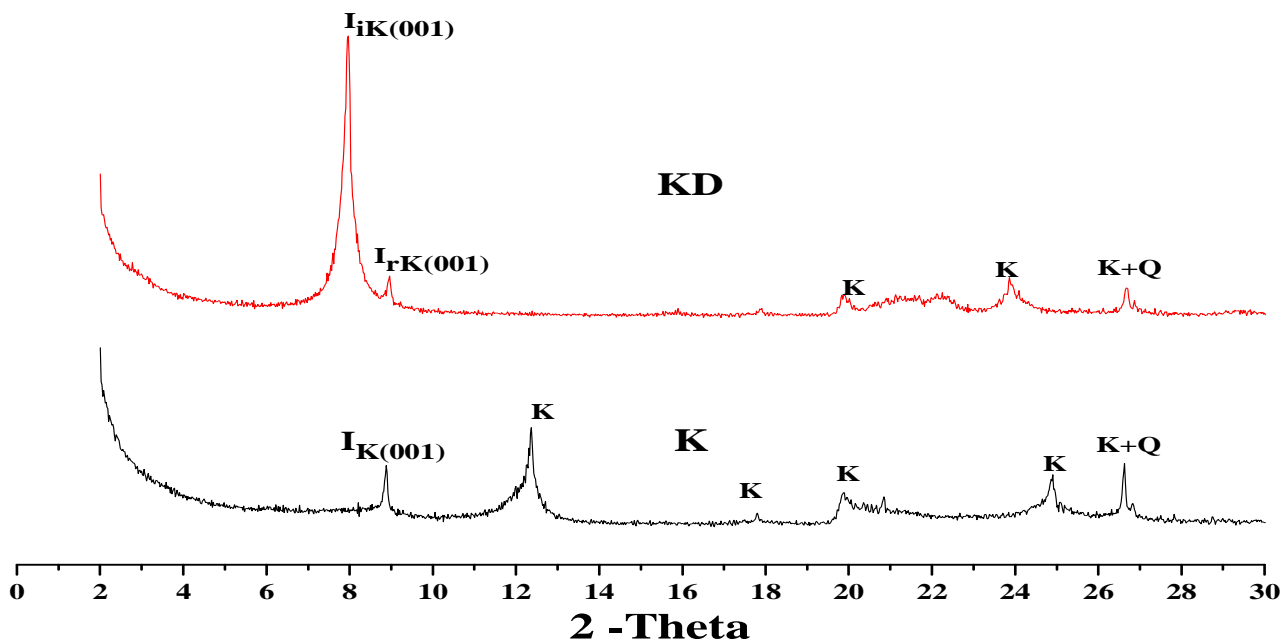

Fig. 1. XRD patterns of unmodified kaolin (K) and modified by DMSO (KD)

With an intercalation rate of $98 \%$, we can say that our clay is easily intercalated compared to other kaolinites. Indeed, Mbey et al. [31] found a ratio of $62.4 \%$ for the intercalation of DMSO in a Cameroonian kaolinite. Zhang and Xu [32] achieved an $80 \%$ intercalation rate when preparing kaolinite/DMSO composite under activated microwave radiation.

\section{FTIR analysis}

The IR spectra were acquired through a Fourier transform spectrometer. The device used is SHIMADZU (FTIR-8400S). The FTIR spectra of all our samples are shown in Figure 2.

The intercalation of DMSO caused considerable changes in vibrational spectra. The intercalation reaction destroys the inherent hydrogen bonding of the starting material and emphasizes new bonds, which changes the intensity and location of the characteristic bands of the hydroxyl groups of the inner surface. The disappearance of the band at $3703 \mathrm{~cm}^{-1}$ proves that $\left(\mathrm{CH}_{3}\right)$ SO interacts with the hydroxyls of the inner surface of the clay, through new hydrogen bonds with the $\mathrm{S}=\mathrm{O}$ groups.

The presence of intermediate DMSO is also evidenced by the asymmetric stretching $\left(v_{\mathrm{as}} \mathrm{CH}_{3}\right)$ and symmetric stretching $\left(v \mathrm{~s} \mathrm{CH}_{3}\right)$ of the methyl $\mathrm{C}-\mathrm{H}$ at 3023 and $2929 \mathrm{~cm}^{-1}$, respectively. The 1405 and $1427 \mathrm{~cm}^{-1}$ bands are assigned to $\delta$ as $\mathrm{CH}_{3}$ and $\delta \mathrm{CH}_{3}$. 


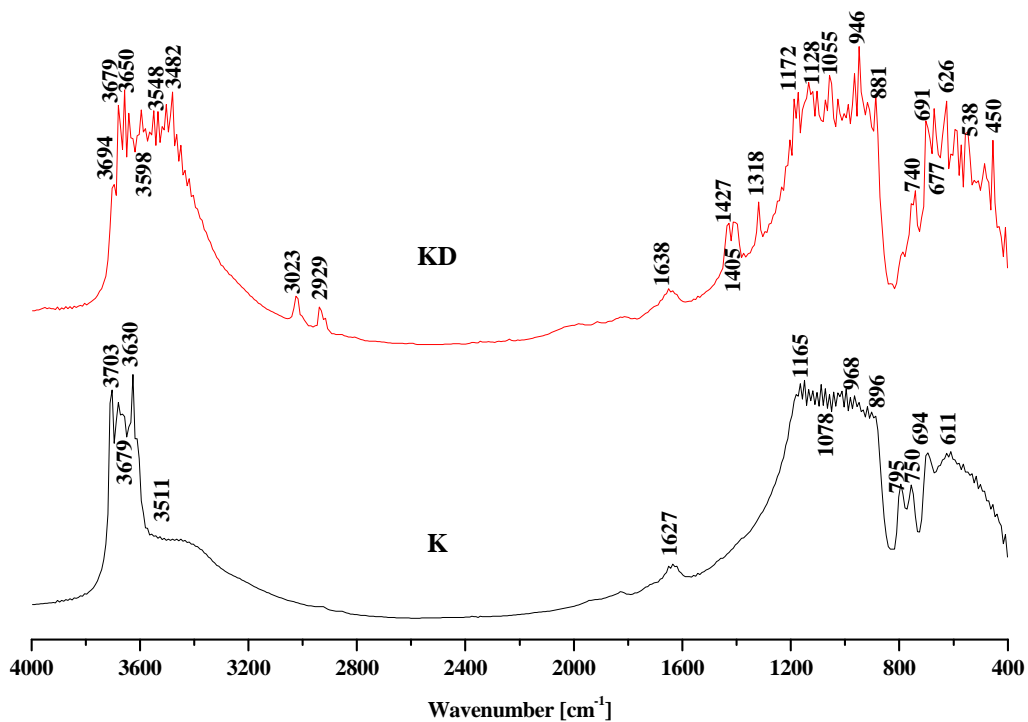

Fig. 2. FTIR spectra of the unmodified kaolin (K) and DMSO-intercalated kaolin (KD)

\section{Scanning electron microscopy}

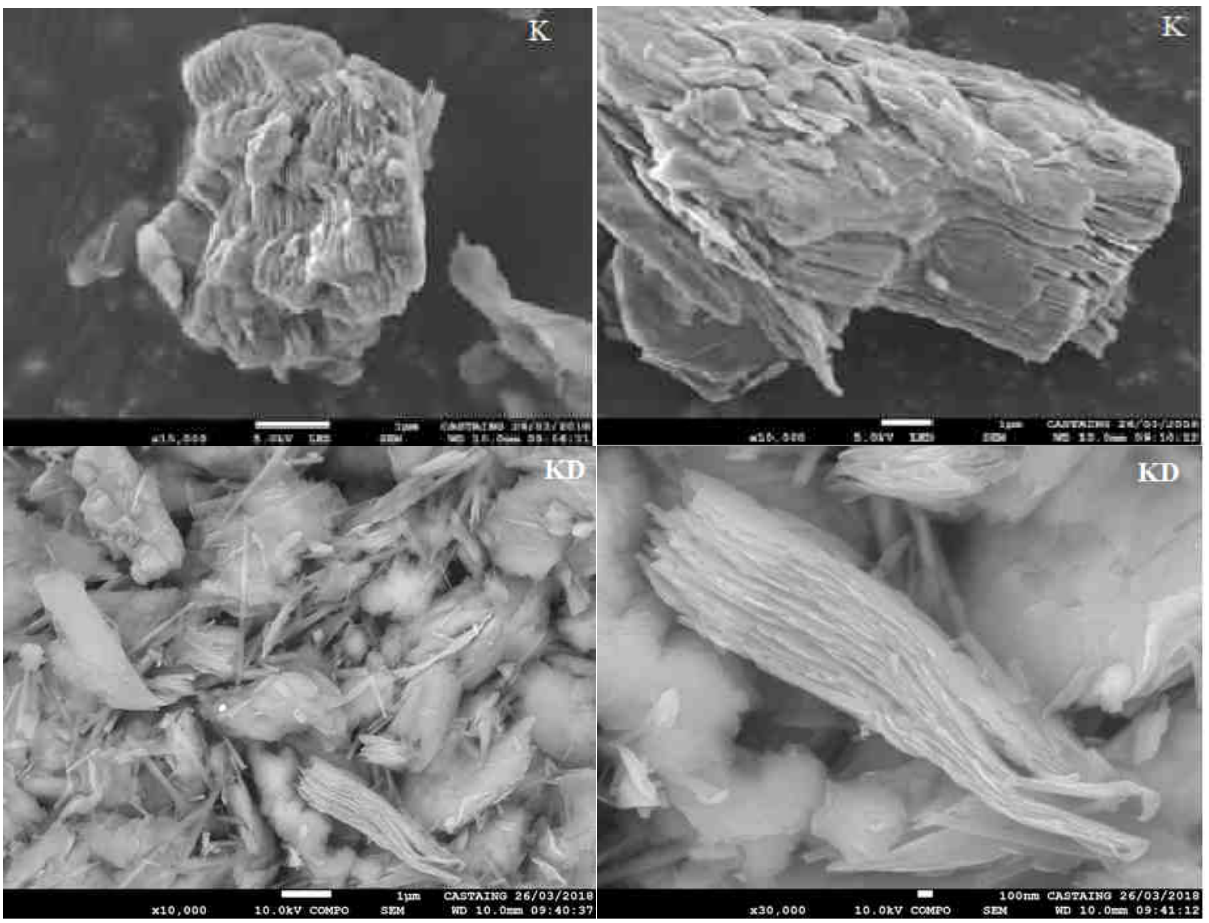

Fig. 3. Scanning electron microscopy images of unmodified kaolin (K) and DMSO-intercalated kaolin (KD) 
The surface morphology of Tamazert kaolin, respected by SEM (Fig. 3), indicates the presence of well crystallized kaolinite and hexagonal particles of different sizes.

The intercalation of the clay by DMSO (KD) caused a great textural modification of our clay. Indeed, the kaolinite plates show a partial separation and disintegration of the particles, corresponding to their interaction with the organic molecules

\section{Adsorption of BM}

\section{Effect of adsorbent concentration}

The amount of adsorbed dye per unit mass of clay decreased as the solid/liquid ratio increased (Fig. 4). This decrease can be explained by the fact that the presence of a large amount of adsorbent reduces the number of adsorption sites per unit mass, which causes a decrease in adsorption. On the other hand, increasing the amount of adsorbent will scream an aggregation of the particles which results in the decrease of the total area and an increase in the length of the diffusion path. These two phenomena contribute to the decrease of the adsorbed quantity per unit mass [33, 34]. The largest amount adsorbed at equilibrium was observed at a ratio of $1 \mathrm{~g} / \mathrm{dm}^{3}$, with a methylene blue removal rate greater than $97 \%$ for both materials. Thus, $1 \mathrm{~g} / \mathrm{dm}^{3}$ was considered in all subsequent experiments.

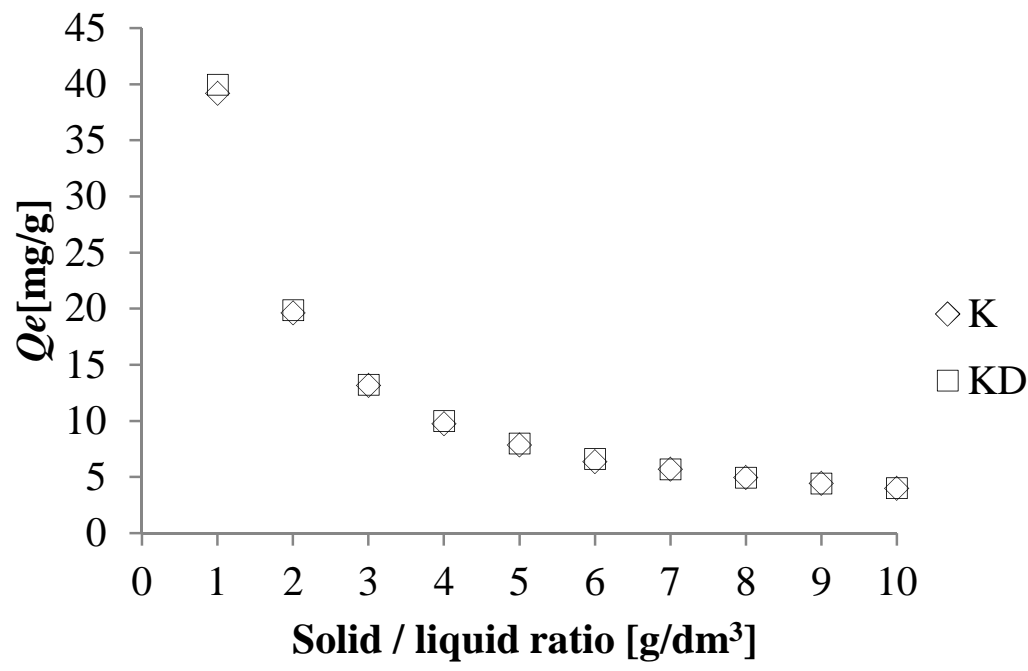

Fig. 4. Effect of solid/solution concentration on the amount adsorbed by the kaolin solids

\section{Effects of $p H$}

$\mathrm{pH}$ is one of the factors influencing adsorption, by modifying the surface charge of the adsorption. In this study we followed the effect of $\mathrm{pH}$ on the elimination of methylene blue by different materials, for an initial concentration of $40 \mathrm{mg} / \mathrm{dm}^{3}$. Figure 5 shows the evolution of the quantity adsorbed at equilibrium by each material as a function of the $\mathrm{pH}$ of the solution The retention capacity of methylene blue increases rapidly in the range of $\mathrm{pH}$ from 2 to 5 and then stabilizes for both materials. The strong adsorption in this $\mathrm{pH}$ 
range can be explained by the competitive effect between the $\mathrm{H}^{+}$ions and the cationic dye. For the rest of the experiment, we adjusted the $\mathrm{pH}$ of the solutions to 5.

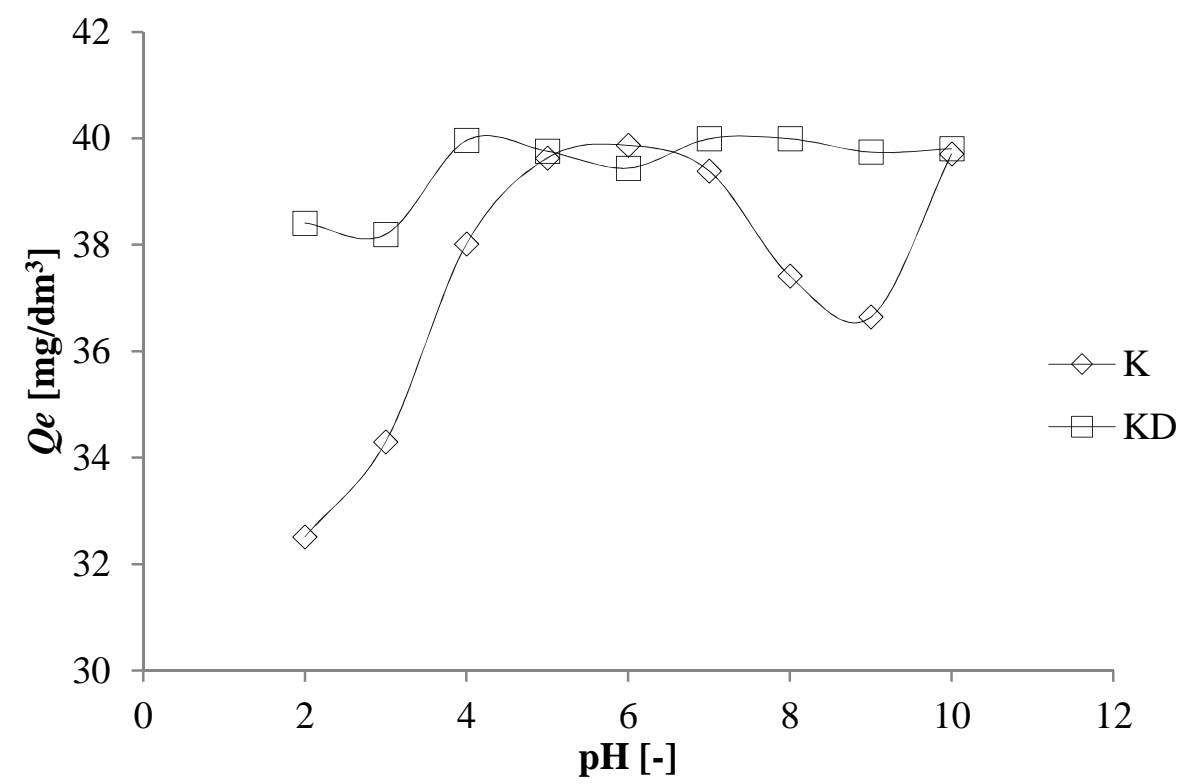

Fig. 5. Effect of $\mathrm{pH}$ on the adsorption of methylene blue onto the kaolin solids

\section{Effect of contact time}

In order to study the effect of time on the adsorption of methylene blue by the two materials, a series of experiments were carried out at $\mathrm{pH}=5$ and at time intervals ranging from 1 to 120 minutes (Fig. 6). The adsorption was quick in the first ten minutes, due to the availability of surface negatively charged sites. The curves then tend towards a landing. Equilibrium is reached after 30 minutes of contact for beyond the change was not significant.

The parameters corresponding to the kinetic models used are reported in Table 3. The values of the coefficients of determination are extremely low, $<0.47$, for the first model. The adsorption of BM by two materials does not follow Lagergren's equation of the first order (figure not shown). The results show that the adsorption of methylene blue follows perfectly the pseudo-second-order model and that of all the materials (Fig. 7). The coefficients of determination, $R^{2}$, tend towards 1 . The calculated values, $Q e(\mathrm{cal})$, also agree very well with the experimental data (Table 2). Considering the initial adsorption rate, $h$, DMSO-modified kaolinite adsorbs methylene blue very quickly compared to the starting material.

In adsorption from solution, diffusion from the solid-liquid interface to the interior of the solid particles plays a very important role. Whether the process of adsorption is controlled by this type of intra-particle diffusion, is tested by plotting $Q t$ vs. $t^{0.5}$ (figure not shown). The curves were linear with regression coefficients equal to 1 (Table 3 ). The DMSO-modified sample promotes intraparticle diffusion of methylene blue 
$\left(K_{i d}=3.09\right)$ compared with purified kaolinite $\left(K_{i d}=2.22\right)$. The thickness of the boundary layer, $C$, remains constant.

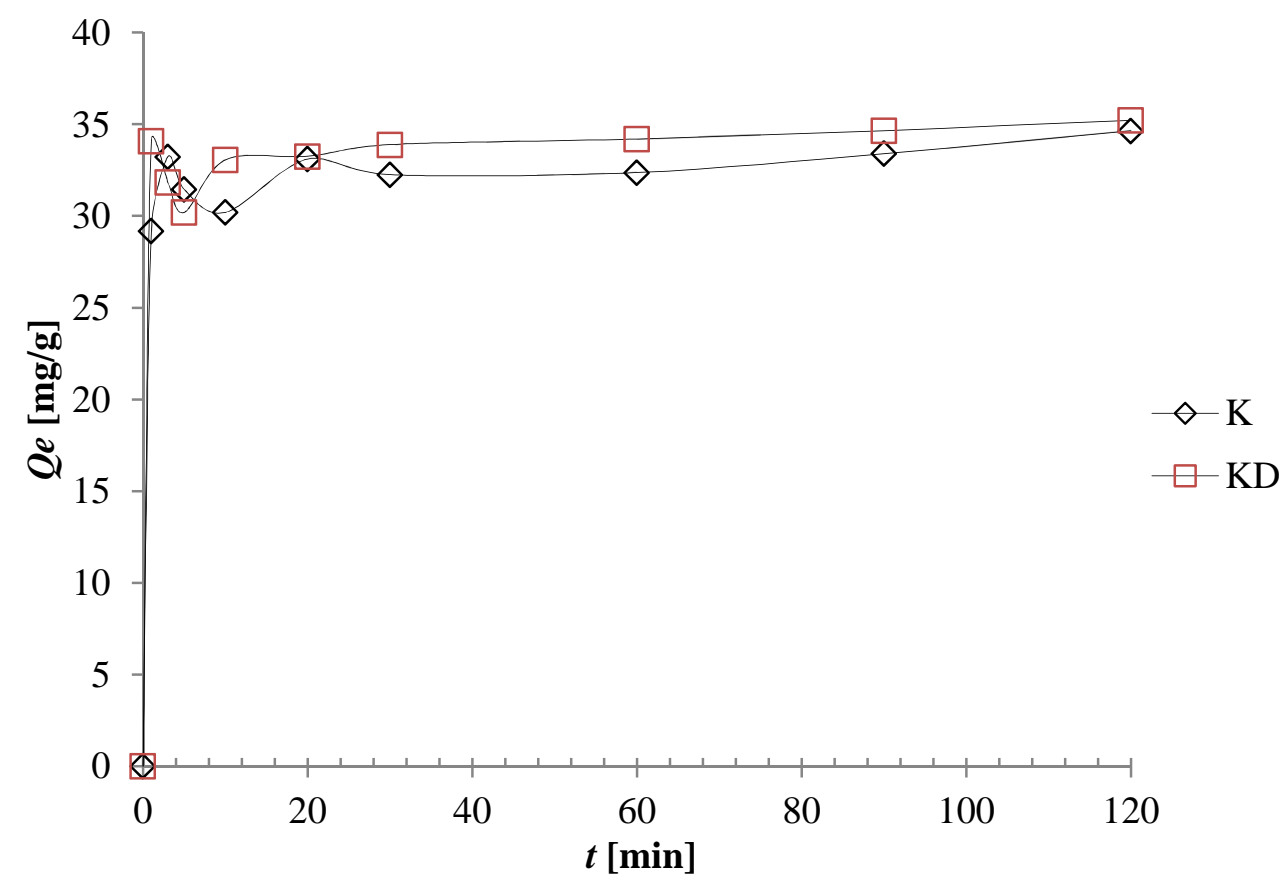

Fig. 6. Effect of contact time on the adsorption of methylene blue onto the kaolin solids

Table 3

Kinetic parameters methylene blue adsorption onto the kaolin solids

\begin{tabular}{|c|c|c|c|}
\hline \multirow{2}{*}{ Kinetic models } & \multirow{2}{*}{ Parameters } & K & Adsorbents \\
\cline { 3 - 4 } & $Q e(\exp )[\mathrm{mg} / \mathrm{g}]$ & 34.64 & 35.22 \\
Pseudo-first order & $K_{1}\left[\mathrm{~min}^{-1}\right]$ & 0.009 & 0.010 \\
& $Q e($ cal $)[\mathrm{mg} / \mathrm{g}]$ & 3.10 & 2.25 \\
& $R^{2}$ & 0.47 & 0.42 \\
\hline \multirow{3}{*}{ Pseudo-second } & $Q e(\exp )[\mathrm{mg} / \mathrm{g}]$ & 34.64 & 35.22 \\
order & $Q e(\mathrm{cal})[\mathrm{mg} / \mathrm{g}]$ & 34.25 & 35.09 \\
& $K_{2}\left[\mathrm{~g} \cdot(\mathrm{mg} \cdot \mathrm{min})^{-1}\right]$ & 0.03 & 0.04 \\
& $h\left[\mathrm{mg} \cdot(\mathrm{g} \cdot \mathrm{min})^{-1}\right]$ & 34.01 & 51.02 \\
Intraparticle diffusion & $R^{2}$ & 0.99 & 0.99 \\
model & $K_{i d}\left[\mathrm{mg} / \mathrm{g} \cdot \mathrm{min}^{-1 / 2}\right]$ & 2.22 & 3.09 \\
& $C[\mathrm{mg} / \mathrm{g}]$ & 23.17 & 23.28 \\
\end{tabular}

The stagnation of $C$ reveals that the boundary layer has no effect on the limitation of the adsorption kinetics. This implies that intraparticle diffusion is the only factor responsible for adsorption rate. 


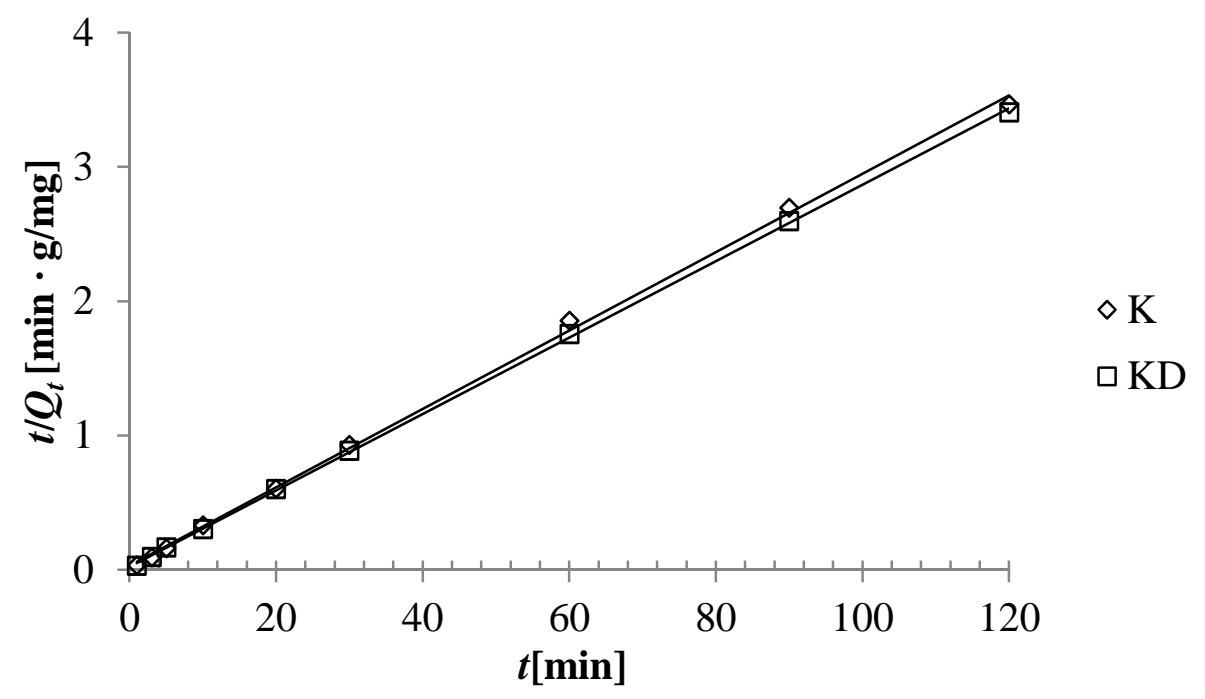

Fig. 7. Application of the pseudo-second model

\section{Adsorption equilibrium}

\section{Isotherms}

Using the classification of Giles et al. [35], the adsorption isotherms of methylene blue are of $\mathrm{L}$ type (figure not shown). The $\mathrm{L}$ shape means that there is no strong competition between the solvent and the sorbate to occupy the sorbent surface sites. The initial curvature of the L curve shows that the contaminant has a high affinity for the surface. The adsorption isotherms of BM by kaolinite indicate that the adsorbed quantity increases with increasing temperature. This suggests an endothermic effect. This increase can be attributed to an increase in the number of available active surface sites or to an increase in the mobility of methylene blue cations [33].

On the other hand, for the adsorption isotherms of methylene blue by DMSO-modified kaolinite, the opposite effect is observed. Indeed, the rise in temperature causes a decrease in the amount adsorbed at equilibrium. This shows that the adsorption of this dye is favoured at low temperature during the adsorption of the cationic dye (methylene blue) by the kaolinite intercalated by DMSO [36]. The adsorption process was exothermic. Whatever the initial concentration and whatever the temperature, the adsorbed quantities at equilibrium of the BM by the modified kaolinite $(\mathrm{KD})$ are greater than those of the starting material $(\mathrm{K})$.

Fitting the models to the experimental data

The parameters of the models used to describe the equilibrium between BM and kaolinitic solids are listed in Table 4.

The Langmuir model does not describe all the experimental isotherms because the $R^{2}$ values are relatively low. According to Table 4, the fit of the experimental data according to the Freundlich model appears better compared to that of Langmuir. The coefficient of determination is $\geq 0.87$. This suggests that there are different types of adsorption sites of 
different energy, distributed according to an exponential law depending on the heat of adsorption. This distribution of interaction energies is explained by the heterogeneity of the sites. The adsorption capacity $K_{F}$ increases with the temperature for both materials. The coefficient $\mathrm{n}$ varies with the temperature; it characterizes the intensity of the adsorption. Whatever the sample, $n>1$ indicates a favourable adsorption process. Adsorption is not always a simple process, because different interactions can be at the origin of the association of a chemical (adsorbate) with a solid (adsorbent). These interactions can be electrostatic, Van der Waals type, hydrogen bond, polar, ion exchange.

Table 4

Isotherm parameters for the BM adsorption at different temperatures

\begin{tabular}{|c|c|c|c|c|c|c|c|}
\hline \multirow{3}{*}{$\begin{array}{c}\text { Isotherms } \\
\text { models }\end{array}$} & \multirow{3}{*}{ Parameters } & \multicolumn{6}{|c|}{ Adsorbents } \\
\hline & & \multicolumn{3}{|c|}{$\mathbf{K}$} & \multicolumn{3}{|c|}{ KD } \\
\hline & & 298 K & $313 \mathrm{~K}$ & $323 \mathrm{~K}$ & $298 \mathrm{~K}$ & $313 \mathrm{~K}$ & $323 \mathrm{~K}$ \\
\hline \multirow{5}{*}{ Langmuir } & $Q e[\mathrm{mg} / \mathrm{g}]$ & 147.43 & 179.35 & 194.88 & 209.43 & 187.61 & 143.06 \\
\hline & $Q m[\mathrm{mg} / \mathrm{g}]$ & 212.77 & 178.35 & 204.08 & 243.90 & 212.77 & 147.06 \\
\hline & $K_{L}\left[\mathrm{dm}^{3} / \mathrm{mg}\right]$ & 0.013 & 0.035 & 0.054 & 0.016 & 0.021 & 0.038 \\
\hline & $R^{2}$ & 0.309 & 0.949 & 0.973 & 0.668 & 0.815 & 0.963 \\
\hline & $E[\%]$ & 34.57 & 25.92 & 33.34 & 44.64 & 39.65 & 40.63 \\
\hline \multirow{4}{*}{ Freundlich } & $K_{F}\left[\mathrm{dm}^{3} / \mathrm{g}\right]$ & 12.258 & 23.512 & 23.122 & 22.087 & 24.829 & 23.310 \\
\hline & $n$ & 2.156 & 3.225 & 2.463 & 2.840 & 3.104 & 3.209 \\
\hline & $R^{2}$ & 0.894 & 0.869 & 0.915 & 0.873 & 0.873 & 0.961 \\
\hline & $E[\%]$ & 21.35 & 19.29 & 18.92 & 29.48 & 25.73 & 14.21 \\
\hline \multirow{5}{*}{$\begin{array}{l}\text { Redlich- } \\
\text { Peterson }\end{array}$} & $M[\mathrm{mg} / \mathrm{g}]$ & 0.006 & 0.306 & 0.763 & 733.809 & 0.047 & 0.322 \\
\hline & $\beta$ & 0.301 & 0.577 & 0.632 & 0.313 & 0.438 & 0.635 \\
\hline & $K_{R P}\left[\mathrm{dm}^{3} / \mathrm{mg}\right]$ & 12845 & 14355 & 18528 & 135539 & 12459 & 68946 \\
\hline & $R^{2}$ & 0.988 & 0.994 & 0.976 & 0.980 & 0.975 & 0.972 \\
\hline & $E[\%]$ & 13.53 & 6.85 & 20.21 & 29.01 & 26.44 & 13.19 \\
\hline
\end{tabular}

The adsorption phenomenon for this type of system is therefore very complex. Models with two parameters to adjust, such as those of Langmuir and Freundlich, would not be able to explain the equilibrium relationships. For this reason, we used the Redlich-Peterson model to describe experimental isotherms. From the values of the coefficient of determination, $R^{2}$, we can affirm that the Redlich-Peterson equation very suitably describes the BM adsorption isotherms by the two materials (Fig. 8). Whatever the temperature $R^{2} \geq 0.970$ (Table 4).

The $K_{R P}$ values showed that the adsorption capacity increased with increasing temperature for the purified kaolinite and decreased for the intercalated kaolinite. Similar behaviour has also been observed with experimental isotherms. The maximum amount absorbed, $M$, evolves in the same direction as $K_{R P}$. The surface heterogeneity factor, $\beta$, depends on the surface properties, the degree of crystallinity and the distribution of the active sites. The value of this parameter is $<1$ for all solids. This result is a sign of favourable adsorption. 
a)

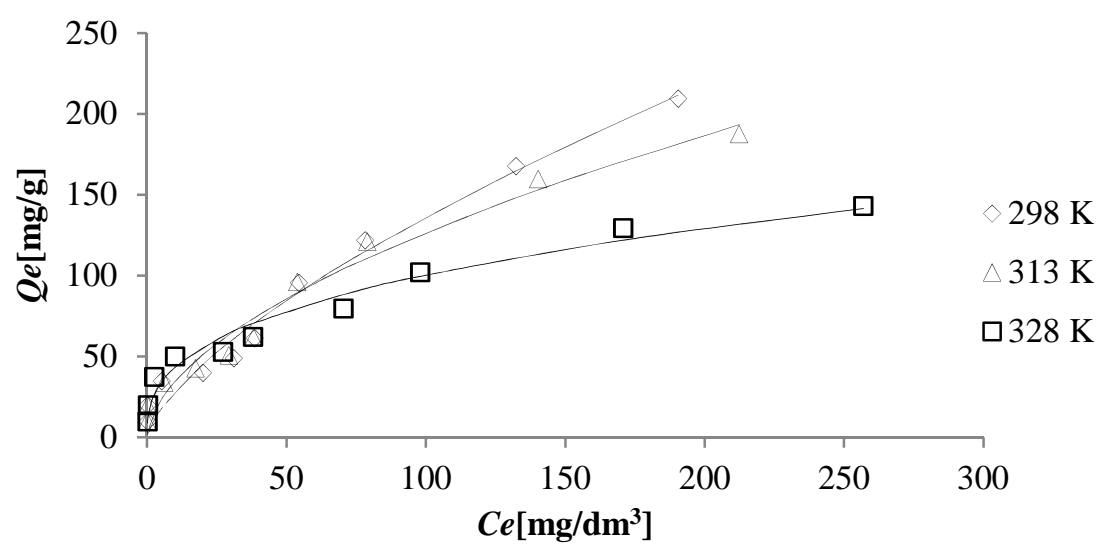

b)

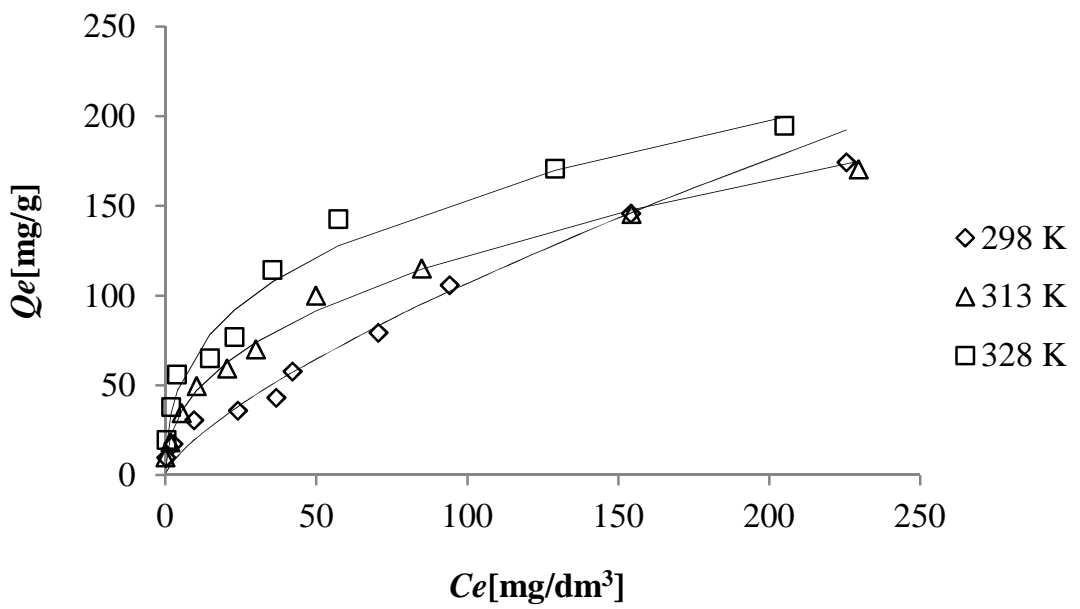

Fig. 8. Adsorption isotherms of BM, according to the experimental data and RP model: a) DMSO-intercalated kaolin, b) unmodified kaolin

\section{Thermodynamic parameters}

The thermodynamic quantities $\Delta H^{\circ}, \Delta S^{\circ}$ and $\Delta G^{\circ}$ are given in Table 5 . In the case of a physisorption, the variation of the free energy is between 0 and $20 \mathrm{~kJ} / \mathrm{mol}$ [37], as for the chemisorption it is in the range $80-400 \mathrm{~kJ} / \mathrm{mol}$ [38]. From these thermodynamic values, it can be said that Tamazert kaolin has changed its behaviour with respect to the elimination of methylene blue after intercalation with DMSO. Indeed, before intercalation the physisorption was endothermic $\left(\Delta H^{\circ}>0\right)$ disordered $\left(\Delta S^{\circ}>0\right)$ and spontaneous $\left(\Delta G^{\circ}<0\right)$. The Gibbs energy increases with temperature, which has the effect of accentuating this spontaneous character. After the modification, the physisorption became exothermic $\left(\Delta H^{\circ}<0\right)$ ordered $\left(\Delta S^{\circ}<0\right)$ and not spontaneous $\left(\Delta G^{\circ}>0\right)$. This non-spontaneity increases with the rise in temperature. 
Thermodynamic parameters for adsorption of methylene blue by different materials

\begin{tabular}{|c|c|c|c|c|c|c|}
\hline \multicolumn{7}{|c|}{ BM } \\
\hline Samples & $\Delta \boldsymbol{H}^{\circ}$ & $\Delta \boldsymbol{S}^{\circ}$ & \multicolumn{3}{|c|}{$\Delta \boldsymbol{G}^{\circ}[\mathbf{k J} / \mathbf{m o l}]$} & $\boldsymbol{R}^{2}$ \\
\hline & {$[\mathbf{k J} / \mathbf{m o l}]$} & {$[\mathbf{k J} /(\mathbf{m o l} \cdot \mathbf{K})]$} & $\mathbf{2 9 8 ~ K}$ & $\mathbf{3 1 3} \mathbf{~ K}$ & $\mathbf{3 2 8} \mathbf{~ K}$ & \\
\hline $\mathrm{K}$ & 10,445 & 0,036 & -0.205 & -0.741 & -1.277 & 0.990 \\
\hline $\mathrm{KD}$ & -2.597 & -0.056 & 14.114 & 1.955 & 15.797 & 0.999 \\
\hline
\end{tabular}

\section{Conclusion}

The chemical treatment with DMSO caused a considerable modification of our clay. Indeed, X-ray diffraction and Fourier transform infrared confirmed the insertion of DMSO into the interfoliar space. XRD showed an increase in the basal spacing of the 001 planar plane reflection, from 7.16 to $11.22 \AA$, which is an intercalation rate of $98 \%$.

Scanning electron micrographs showed partial separation and disintegration of kaolinite particles after intercalation of Tamazert kaolin with DMSO. It has been found that the adsorption process mainly follows pseudo-second-order kinetics and intraparticle diffusion. The isotherms were better adjusted by the Redlich-Peterson model $\left(R^{2}>0.972\right)$. Isotherms and thermodynamic data show a change in the behaviour of kaolin via elimination of methylene blue. The adsorption was initially ordered spontaneous endothermic disordered and after intercalation it became non spontaneous exothermic ordered.

\section{References}

[1] Nouri L, Hemidouche S, Boudjemaa A, Kaouah F, Sadaoui Z, Bachari K. Int J Biol Macromol. 2020;151:66-84. DOI: 10.1016/j.ijbiomac.2020.02.159.

[2] Yaseen DA, Scholz M. Int J Environ Sci Technol. 2019;16:1193-226. DOI: 10.1007/s13762-018-2130-z.

[3] Boudechiche N, Fares M, Ouyahia S, Yazid H, Trari M, Sadaoui Z. Microchem J. 2019;146:1010-8. DOI: 10.1016/j.microc.2019.02.010.

[4] Aliabadi RS, Mahmoodi NO. J Clean Prod. 2018;179:235-45. DOI: 10.1016/j.jclepro.2018.01.035.

[5] Tomczak E, Blus M. Ecol Chem Eng S. 2016;23(1):175-85. DOI: 10.1515/eces-2016-0012.

[6] Wawrzkiewicz M, Polska-Adach E, Hubicki Z. Adsorption. 2019;25:621-30. DOI: 10.1007/s10450-019-00062-0.

[7] Saputra OA, Prameswari MD, Kinanti VTD, Mayasari OD, Sutarni YD, Apriany K, et al. IOP Conf Ser. Mater Sci Eng. 2017;172:012039. DOI: 10.1088/1757-899X/172/1/ 012039.

[8] Hadj-Otmane C, Ouakouak A, Youcef L, Hai NT. Environ Technol Innov. 2020;19:100872. DOI: 10.1016/j.eti.2020.100872.

[9] Su J, He S, Zhao Z, Liu X, Li H. Colloids Surf A. 2018;554:227-36. DOI: 10.1016/j.colsurfa.2018.06.048.

[10] Calimli MH, Nas MS, Burhan H, Mustafov SB, Demirbas O, Sen F. J Mol Liq. 2020;309:113171. DOI: 10.1016/j.molliq.2020.113171.

[11] Benvenuti J, Fisch A, Zimnoch SJH, Gutterres M. J Environ Chem Eng. 2019;7:103342. DOI: 10.1016/j.jece.2019.103342.

[12] Lagaly G, Ogawa M, Dekany I. Clay mineral-organic interactions. In: Bergaya F, Lagaly G. Handbook of Clay Science: Fundamentals. Chapter 10.3. Amsterdam: Elsevier; 2013. ISBN: 9780080457635.

[13] Mehdi K, Bendenia S, Lecomte-Nana GL, Batonneau-Gener I, Rossignol F, Marouf-Khelifa K, et al. Chem Papers. 2019;73:131-9. DOI: 10.1007/s11696-018-0558-8.

[14] Zang S, Liu Q, Gao F, Ma R, Wu Z, Teppen BJ. Appl Clay Sci. 2018;158:204-10. DOI: 10.1016/j.clay.2018.03.032.

[15] Mako E, Kovacs A, Kristof T. Appl Clay Sci. 2019;182:105287. DOI: 10.1016/j.clay.2019.105287.

[16] Cheng H, Li K, Liu Q, Zhang S, Li X; Frost RL. J Therm Anal Calorim. 2014;117:1231-9. DOI: 10.1007/s10973-014-3934-9.

[17] Cheng H, Liu Q, Yang J, Du X, Frost RL. Appl Clay Sci. 2010;50:476-80. DOI: 10.1016/j.clay.2010.09.011. 
[18] Cheng H, Liu Q, Zhang J, Yang J, Frost RL. J Colloid Interface Sci. 2010;348:355-9. DOI: 10.1016/j.jcis.2010.05.006.

[19] Mgbemena CO, Ibekwe NO, Mohamed AAP, Sukumar R, Menon ARR. J Surf Eng Mater Adv Technol. 2013;3:163-8. DOI: 10.4236/jsemat.2013.33021.

[20] Liu Q, Cheng H, Zhou Y. J Phys Chem Solids. 2020;136:109170. DOI: 10.1016/j.jpcs.2019.109170.

[21] Zang S, Liu Q, Cheng H, Gao F, Liu C, Teppen BJ. Appl Clay Sci. 2018;151:46-53. DOI: 10.1016/j.clay.2017.10.022.

[22] Wilson MJ. A Handbook of Determinative Methods in Clay Mineralogy. London: Blackie \& Son Ltd; 1987. ISBN: 9780412009013.

[23] Mahrez M, Bendenia S, Marouf-Khelifa K, Batonneau-Gener I, Khelifa A. Compos Interfaces. 2015;22:403-17. DOI: 10.1080/09276440.2015.1036581.

[24] Bujdak J. Appl Clay Sci. 2020;191:105630. DOI: 10.1016/j.clay.2020.105630.

[25] Tran HN, You SJ, Hosseini-Bandegharaei A, Chao HP. Water Res. 2017;120:88-116. DOI: 10.1016/j.watres.2017.04.014.

[26] Largitte L, Pasquier R. Chem Eng Res Des. 2016;109:495-504. DOI: 10.1016/j.cherd.2016.02.006.

[27] Al-Ghouti MA, Razavi MM. Environ Technol Innov. 2020;17:100614. DOI: 10.1016/j.eti.2020.100614.

[28] Ayawei N, Ebelegi AN, Wankasi D. J Chem. 2017;3039817:1-11. DOI: 10.1155/2017/3039817.

[29] Al-Ghouti MA, Da'ana DA. J Hazard Mater. 2020;393:122383. DOI: 10.1016/j.jhazmat.2020.122383.

[30] Salaa F, Bendenia S, Lecomte-Nanab GL, Khelifa A. Chem Eng J. 2020;396:125226. DOI: $10.1016 /$ j.cej.2020.125226.

[31] Mbey JA, Thomas F, Sabouang CJN, Liboum S, Njopwouo D. Appl Clay Sci. 2013;83-84:327-35. DOI: 10.1016/j.clay.2013.08.010.

[32] Zhang XR, Xu Z. Mater Lett. 2007;61(7):1478-82. DOI: 10.1016/j.matlet.2006.07.057.

[33] Kadi S, Lellou S, Marouf-Khelifa K, Schott J, Khelifa A. Desalin Water Treat. 2018;113:213-26. DOI: 10.5004/dwt.2018.22290.

[34] Rawajfih Z, Nsour N. J Chem Thermodyn. 2008;40:846-51.DOI: 10.1016/j.jct.2008.01.005.

[35] Giles CH, Mac Ewan TH, Nakhwa SN, Smith DJ. Chem Soc. 1960;973:3993. DOI: 10.1016/0021-9797(74)90252-5.

[36] Mellouk S, Cherifi S, Sassi M, Marouf-Khelifa K, Bengueddach A, Schott J, et al. Clay Sci. 2009;44(3-4):230-6. DOI: 10.1016/j.clay.2009.02.008.

[37] Bessaha F, Marouf-Khelifa K, Batonneau-Gener I, Khelifa A. Desalin Water Treat. 2016;57:14609-21. DOI: 10.1080/19443994.2015.1063090.

[38] Saeed M, Munir M, Nafees M, Shah SSA, Ullah H, Waseem A. Microporous Mesoporous Mater. 2020;291:109697. DOI: 10.1016/j.micromeso.2019.109697. 